\title{
Principles of Citoportation
}

\author{
Seun Ayoade* \\ Independent Researcher, Oyo State, Nigeria \\ *Corresponding author: Seun Ayoade, Independent Researcher, Oyo State, Nigeria
}

\begin{tabular}{|c|c|}
\hline ARTICLE INFO & ABSTRACT \\
\hline & Citation: Seun Ayoade. Principles of Citoportation. Biomed J Sci \& Tech Res 25(5)-2020. \\
\hline Published: 㓞 February 19, 2020 & BJSTR. MS.ID.004254. \\
\hline
\end{tabular}

\section{Opinion}

I coined the word "Citoportation" from the Latin word for "quickly" (cito) and the Greek word for "carry" (portare). Similar to teleportation, Citoportation proposes to send both living and non-living things across both short and vast distances in incredibly short amounts of time. From Star Trek to the very disturbing The Fly, tales and movies about such instantaneous transfers abound. For decades scientists have considered this idea and many have jettisoned it as a pipe dream not likely to ever be feasible. To the best of my knowledge however no scientist has ever tackled this problem in the light of the macerozymes/cellular dust. Till now! What I propose is changing the state of matter of the entity to be citoported with the aid of microzyman excitation/stimulation and shielding (for inanimate objects) and microzyman excitation, shielding AND mapping (for living things- including man). Citoportation is hinged on microzyman manipulation. Metals and materials encased (and hence strengthened) in microzyman shields pervade the system. Mapping is necessary to prevent scrambling. Never exceeding 500 nanometer in size, microzymas aka cellular dust have long been observed by anatomists, chemists, zoologists, medical doctors, biologists and pharmacists such as professor Bechamp, Henle etc. For some strange reason present day medical textbooks have ignored the work of these scientists and knowledge of the microzymas is largely limited to certain circles.

Microzymas abound in all living things and survive the organism's death. They are the basic unit of living things according to the Germ Terrain Duality Theory of disease [1,2]. To make a distinction between indoor/short range and outdoor/long range citoportation I designate indoor Citoportation "prestoportation" from the Latin word "praesto" (ready). Citoportation is not intended to put the post office and package delivery services out of business.
Nor does it aim to wreck the railway, shipping, trucking, airline and oil and gas industries. There will always be people who want to travel slowly-the old-fashioned way, spending precious time with loved ones and taking in the scenery. Citoportation aims to lower harmful emissions, creating cleaner air and a greener planet. Plus, its applications in instantaneously transporting needed equipment/supplies and the sick and wounded to hospitals will save many lives.

\section{Summary}

Citoportation i.e. teleportation via the microzymas-a novel, lightning fast means of human/inanimate exportation is proposed thus:

a) Map microzymas of individual

b) Excite said microzymas probably with electricity

c) Purpose of such excitation is to cause microzymas to change state/phase of matter of human being from solid/ liquid/gas to plasma, quark gluon plasma or any other suitable state [3-5]

d) Transmit said microzymas/human being via electromagnetic waves

e) Make said microzymas re-assemble at destination in conformity to map.

\section{References}

1. Mister Seun Ayoade (2017) The Differences Between the Germ Theory, the Terrain Theory and the Germ Terrrain Duality Theory. JOJ Nurse Health Care 4(2): 555631.

2. Ayoade S (2017) Koch's Postulates and Germ Terrain Dualism; Cellular Dust as Yet Another Term for Microzymas. J Mol Genet Med 11(4): 297. 
3. Kirill Tuchin (2012) Electromagnetic radiation by quark-gluon plasma in magnetic field. Article in Physical Review C 87(2).

4. B.G. Zakharov (2014) Electromagnetic response of quark-gluon plasma in heavy-ion collisions. pp: 262-266.

ISSN: 2574-1241

DOI: 10.26717/BJSTR.2020.25.004254

Seun Ayoade. Biomed J Sci \& Tech Res

(C) (P) This work is licensed under Creative

Submission Link: https://biomedres.us/submit-manuscript.php
5. Stanisław Mrówczyński, Markus H Thoma (2007) What Do Electromagnetic Plasmas Tell Us about the Quark-Gluon Plasma? Annual Review of Nuclear and Particle Science 57: 61-94.

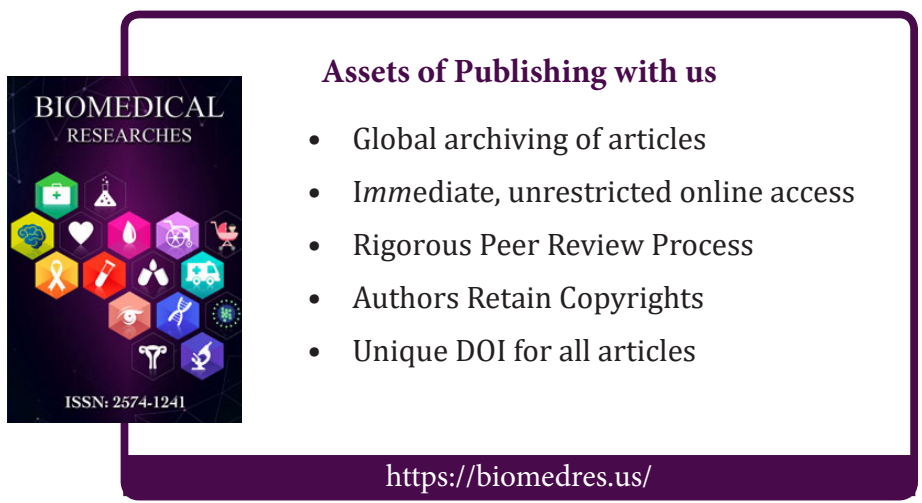

